\title{
Erratum to: Characterization of Five Kinds of Wood Vinegar Obtained from Agricultural and Forestry Wastes and Identification of Major Antioxidants in Wood Vinegar
}

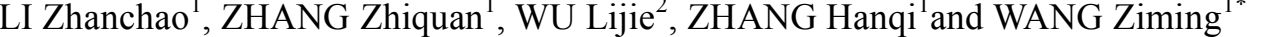

1. College of Chemistry, Jilin University, Changchun 130012, P. R. China;

2. College of Chinese Materia Media, Tianjin University of Traditional ChineseMedicine,

Tianjin 300193, P. R. China

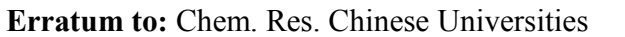

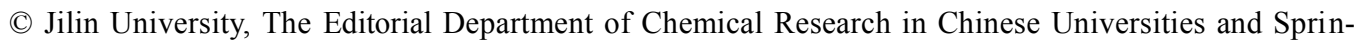

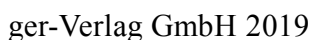

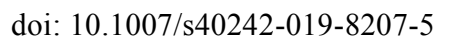

$\square$

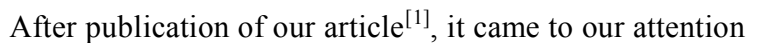

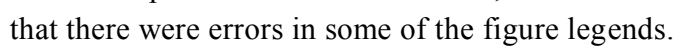

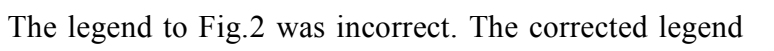

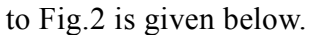

Fig.2 VCEACs of wood vinegar and fractions from wood vinegar

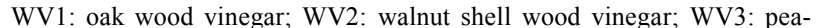

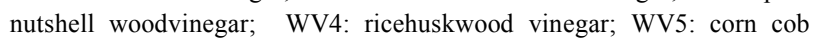

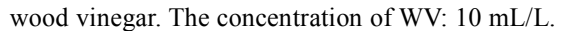

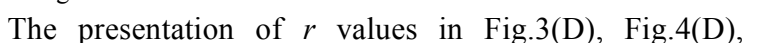

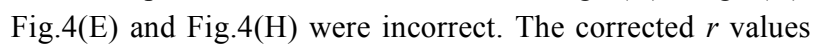

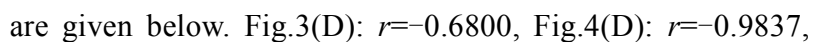

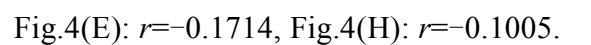

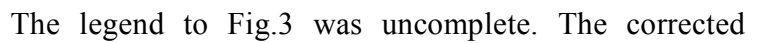

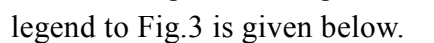

Fig.3 Regression equations and Pearson's correlation coefficients between the contents of components in phenolic extractives and VCEACs of phenolic extractives $\left(n=3, R=\right.$ adjusted $\left.r^{2}\right)$

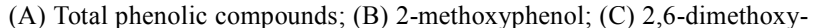

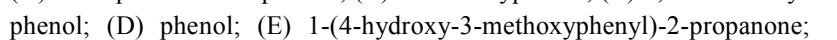

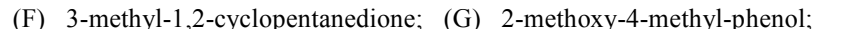

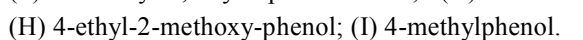

$\square$

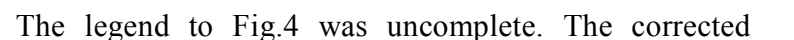

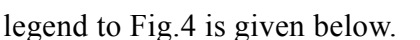

Fig.4 Regression equations and Pearson's correlation coefficients between the contents of components in five kinds of wood vinegar and VCEACs of five kinds of wood $\operatorname{vinegar}\left(n=3, R=\right.$ adjusted $\left.r^{2}\right)$

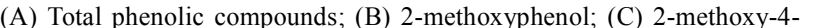

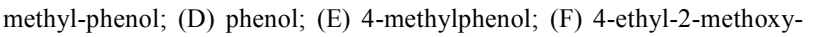

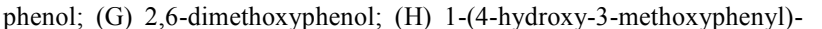

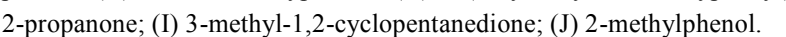
$\square$

\section{References}

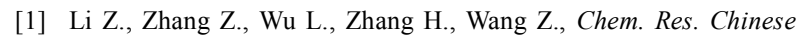

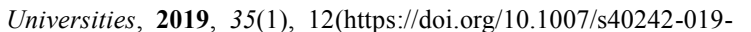
$\square \mid \Pi \| \square$ 